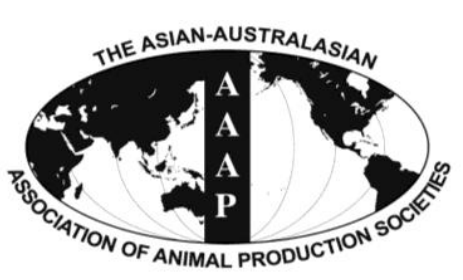

Open Access

Asian Australas. J. Anim. Sci.

Vol. 27, No. 11 : 1577-1583 November 2014

http://dx.doi.org/10.5713/ajas.2014.14280

www.ajas.info

pISSN 1011-2367 elSSN 1976-5517

\title{
Effect of Encapsulating Nitrate in Sesame Gum on In vitro Rumen Fermentation Parameters
}

\author{
Chiedza Isabel Mamvura ${ }^{1, a}$, Sangbuem Cho ${ }^{1,2, a}$, David Tinotenda Mbiriri ${ }^{1}$, Hong-gu Lee ${ }^{3}$, and Nag-Jin Choi ${ }^{1, *}$ \\ ${ }^{1}$ Department of Animal Science, Chonbuk National University, Jeonju 561-756, Korea
}

\begin{abstract}
Encapsulation is a method used to protect material from certain undesirable environments, for controlled release at a more favorable time and place. Animal productivity would be enhanced if feed additives are delivered to be utilized at their site of action, bypassing the rumen where they are likely to be degraded by microbial action. A novel method of encapsulation with sesame gum was used to coat nitrate, a known enteric methane mitigating agent, and tested for the effect on methane reduction and other in vitro fermentation parameters using rumen fluid from cannulated Hanwoo steers. Orchard grass was used as basal diet for fermentation. The treatments were matrix ( $1.1 \mathrm{~g}$ sesame gum $+0.4 \mathrm{~g}$ sesame oil cake) only, encapsulated nitrate (matrix +nitrate [21 mM]), free nitrate $(21$ $\mathrm{mM}$ ), and a control that contained no additive. Analyses of fermentation parameters were done at $0,3,6,9,12,24$, and $48 \mathrm{~h}$ time periods. In comparison to control, both free and encapsulated nitrate produced significantly reduced $(\mathrm{p}<0.01)$ methane $(76 \%$ less $)$ and also the total volatile fatty acids were reduced. A significantly higher $(\mathrm{p}<0.01)$ concentration of ammonia nitrogen was obtained with the encapsulated nitrate treatment $(44 \%)$ compared to the free form $(28 \%)$ and matrix only $(20 \%)(p=0.014)$. This might suggest slow release of encapsulated nitrate so that it is fully reduced to ammonia. Thus, this pioneering study found a significant reduction in methane production following the use of sesame gum encapsulated nitrate that shows the potential of a controlled release system in enhancing sustainability of ruminant production while reducing/eliminating the risk of nitrite toxicity. (Key Words: Encapsulated Nitrate, Sesame Gum, Methane, Rumen, In vitro Fermentation)
\end{abstract}

\section{INTRODUCTION}

Rumen fermentation results in the production of excess $\mathrm{H}_{2}$, which needs to be removed as methane for efficient microbial growth and continual fermentation (Martin et al., 2010). Methane emission, however, is a cause for concern for the environment due to its effects on global warming. It also represents an energy loss of $2 \%$ to $12 \%$ of the gross energy of feed (Johnson and Johnson, 1995; Goel and Makkar, 2012). Thus for environmental and productivity

\footnotetext{
* Corresponding Author: Nag-Jin Choi. Tel: +82-63-270-2579, Fax: +82-63-270-2612, E-mail: nagjin@jbnu.ac.kr

${ }^{2}$ Animal Resources Research Center, Konkuk University, Seoul 143-701, Korea.

3 Department of Animal Science and Technology, College of Animal Bioscience and Technology, Konkuk University, Seoul 143-701, Korea.

${ }^{a}$ These authors contributed equally to this work.

Submitted Apr. 17, 2014; Revised Jun. 8, 2014; Accepted Jun. 28, 2014
}

reasons, there is need for ways to decrease methane production from ruminants.

Nitrate is a proven additive that reduces enteric methane production (Van Zijderveld et al., 2010). Nitrate has a higher affinity for $\mathrm{H}_{2}$ than $\mathrm{CO}_{2}$ and thus acts as a $\mathrm{H}_{2}$ sink, diverting from methane formation to nitrite and ammonia (Ungerfeld and Kohn, 2006; Nolan et al., 2010). Nitrate inclusion as a feed additive has the advantage of adding ammonia nitrogen (ammonia-N) to the rumen, which is the end-product in nitrate reduction, and is important for microbial growth. Nitrate reduction could be more efficient for energy than methane production, thus promoting microbial growth (Nolan et al., 2010). However, nitrite, an intermediate of nitrate reduction, carries the risk of toxicity and causing methemoglobinemia (Zhou et al., 2012).

Application of microencapsulation has been used over time mainly in the food, agrochemical and pharmaceutical industries. In the animal nutrition industry encapsulation has only been in use for about a decade (Emanuele, 2006). 
The reasons for use of this technique range from stabilizing the core material, masking unpleasant flavors, colors, or odors, controlling the oxidative reaction, extending shelf life, protecting dietary components against nutritional loss, targeted enteric delivery and controlled release in the rumen (Anal and Singh, 2007; Nazzaro et al., 2012). Microspheres can be made to release their contents by various means. These include fracture by heat, solvation, diffusion or pressure (Brannon-Peppas, 1997). Previous encapsulation trials have focused on delivery of vitamin $\mathrm{C}$, which is sensitive to heat, moisture and oxidation (Cusack et al., 2005), choline, which plays a major role in lipid transport (Cooke et al., 2007), protection of polyunsaturated fatty acids against microbial hydrogenation (Lee et al., 2004), probiotics (Ridwan et al., 2010) as well as antimicrobial organic acids (Wood et al., 2009). Overall productivity increases when bioactives are utilized precisely where they are needed and encapsulation helps to achieve this goal.

Encapsulation has been limited at a commercial level because it is costly (Emanuele and Putnam, 2006). Finding cheaper alternatives would be of help. In this study, sesame oil gum was used to encapsulate nitrate. The method of using sesame gum as encapsulating material has several advantages. It is an economically-viable and eco-friendly method. Natural extraction or use of non-chemical methods is desirable as there are no associated side-effects. Nutritionally, there is an increase of protein and fat bioavailability to the animal, together with essential and nonessential amino acids associated with the sesame oil gum (Deshpande et al., 1996; Kochhar, 2011). Toxicity due to nitrite accumulation can be potentially reduced (Zhou et al., 2012), as there will be slow release of the encapsulated nitrate. To the best of our knowledge this is the first time such a study has been undertaken. The aim was to investigate the effects of encapsulation of nitrate on in vitro rumen fermentation in cattle.

\section{MATERIALS AND METHODS}

\section{Encapsulation of nitrate}

Sesame seed oil and cake were obtained from a local market (Jeonju, South Korea). Encapsulation of nitrate with sesame seed oil was performed according to Macgregor (2007) and Aly (1992) with modifications. Briefly, $100 \mathrm{~g}$ of oil and $3 \mathrm{~mL}$ of water were mixed and the mixture brought to $90^{\circ} \mathrm{C}$ with stirring for $30 \mathrm{~min}$ followed by centrifugation (4,000 rpm, $30 \mathrm{~min}$ ). Supernatant was discarded and the remaining gum was collected. A measure of $1.1 \mathrm{~g}$ was thoroughly mixed with $1,784.79 \mathrm{mg}$ nitrate to make $21 \mathrm{mM}$ final concentration when mixed with buffered rumen fluid. Sesame oil cake (SOC) was added at $0.4 \mathrm{~g}$ for a carrier and to make for easier handling. The encapsulating material, 1.1 $\mathrm{g}$ of gum mixed with $0.4 \mathrm{~g}$ SOC, was prepared separately without any core to make another treatment or additive.

\section{Inoculum}

Rumen contents were collected from two cannulated Hanwoo (Korean native) steers before morning feeding $(08: 00 \mathrm{~h})$. The contents were filtered through four layers of cheesecloth. The rumen fluid was stored in a thermos flask and immediately taken to the laboratory. The flask and contents were stored at $39^{\circ} \mathrm{C}$.

\section{In vitro fermentation}

Substrate used was orchard grass, ground through a 1 $\mathrm{mm}$ screen. The following treatments were used for in vitro fermentation: control (no additive), $21 \mathrm{mM}$ nitrate, $21 \mathrm{mM}$ nitrate encapsulated in gum and SOC, and matrix only, which comprised SOC and gum. Rumen fluid was mixed with McDougall's buffer (McDougall, 1948) in a 1:4 ratio. An amount of $50 \mathrm{~mL}$ of this buffered rumen fluid was dispensed into individual $250 \mathrm{~mL}$ serum bottles which had pre-weighed $0.5 \mathrm{~g}$ substrate and additive. $\mathrm{CO}_{2}$ was used to gas all bottles to maintain anaerobic conditions. Upon inoculation, each serum bottle was immediately crimpsealed with a butyl rubber stopper and an aluminium cap. Rumen fermentation parameters were analyzed in triplicate at $0,3,6,9,12,24$, and $48 \mathrm{~h}$ intervals following incubation at $39^{\circ} \mathrm{C}$.

\section{Rumen fermentation parameters}

Total gas produced was measured using a glass syringe connected to a needle, which was inserted through the rubber stopper into the head-space. The collected gas was transferred for storage in aluminum gas packs for subsequent gas analysis. The method of Lopez et al. (1999) for $\mathrm{CH}_{4}$ and $\mathrm{H}_{2}$ quantification was used, with slight modifications. A sample of $1 \mathrm{~mL}$ was withdrawn from the gas pack and injected into a gas chromatograph (GC-7890A, Agilent Technologies, Inc., Palo Alto, CA, USA) fitted with a Thermal Conductivity Detector and a capillary column (Nukol Fused silica capillary column $30 \mathrm{~m} \times 0.25 \mathrm{~mm} \times 0.25$ $\mu \mathrm{m}$ film thickness, Supelco, Bellefonte, PA, USA). Retention times and peaks were compared to known standard gases $\left(\mathrm{CH}_{4}\right.$ and $\mathrm{H}_{2}$, Sigma Aldrich Co., St. Louis, MO, USA, $\mathrm{CO}_{2}$ Cat No. 23402, Supelco analytical, USA).

A Mettler Toledo $\mathrm{pH}$ meter was used to measure $\mathrm{pH}$ of the fermentation fluid. Thereafter, the fermentation fluid was centrifuged (3,000 rpm, $15 \mathrm{~min}$ ), and samples of the supernatant stored at $-20^{\circ} \mathrm{C}$ for volatile fatty acid (VFA) and ammonia-N analyses. The samples for VFA analyses were stabilized by adding $0.2 \mathrm{~mL} 25 \% \quad(\mathrm{w} / \mathrm{v})$ metaphosphoric acid into $1 \mathrm{~mL}$ of sample before storage. VFA were analyzed using a gas chromatograph (GC-7890A, Agilent Technologies, Inc., USA) fitted with a Flame Ionizing Detector and a capillary column (Carbonex Fused 
silica capillary column $30 \mathrm{~m} \times 0.25 \mathrm{~mm} \times 0.25 \mu \mathrm{m}$ film thickness, Supelco, USA) as outlined by Erwin et al. (1961). Ammonia-N was determined according to Chaney and Marbach (1962).

\section{Statistical analysis}

Data were subjected to a two-way analysis of variance using PROC general linear model procedure in SAS (9.2, 2009) for the analysis of significance. The following model was used for all observed patterns;

$$
\mathrm{Y}_{\mathrm{ijk}}=\mu+\mathrm{T}_{\mathrm{i}}+\mathrm{H}_{\mathrm{j}}+(\mathrm{T} \times \mathrm{H})_{\mathrm{ij}}+\mathrm{e}_{\mathrm{ijk}}
$$

where $\mathrm{Y}_{\mathrm{ijk}}$ is the response variable and $\mu$ the overall mean common to all observations, $\mathrm{T}_{\mathrm{i}}$ the $\mathrm{i}^{\text {th }}$ treatment, $\mathrm{H}_{\mathrm{j}}$ the $\mathrm{j}^{\text {th }}$ time, and $(\mathrm{T} \times \mathrm{H})_{\mathrm{ij}}$ the interaction between the $\mathrm{i}^{\text {th }}$ treatment and the $\mathrm{j}^{\text {th }}$ time, while $\mathrm{e}_{\mathrm{ijk}}$ is the residual error.

A t-test was used to analyze the effect of encapsulation between the nitrate treatments.

\section{RESULTS}

Rumen fermentation parameters from each treatment are summarized in Table 1. There was no negative effect produced as a result of encapsulating nitrate. All samples maintained a pH of between 6.75 and 6.80. Free and encapsulated nitrate treatments resulted in a significant decrease $(p<0.01)$ of total gas production of $19 \%$ and $17 \%$, respectively. The matrix produced $12 \%$ more gas than in the control. Ammonia-N was significantly increased $(\mathrm{p}<0.01)$ in all treatments compared to the control. Free and encapsulated nitrate showed elevated ammonia-N production in all incubation times except $48 \mathrm{~h}$ (Figure 1). Encapsulating nitrate produced almost twice (44\%) the

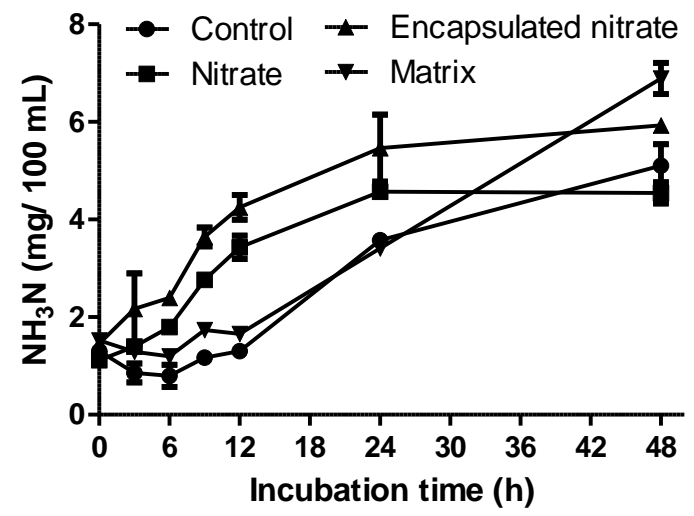

Figure 1. Influence of treatments on ammonia-N accumulation.

amount of ammonia compared to the matrix (20\%) and free nitrate $(28 \%)$ (Table 1). Initially the matrix produced lesser amounts of ammonia-N compared to the nitrate treatments, though it was higher than the control. At $48 \mathrm{~h}$ sampling the matrix had the greatest ammonia- $\mathrm{N}$ concentration (Figure 1).

Total VFAs were significantly reduced by nitrate addition, whether free (12\%) or encapsulated (9\%). The matrix produced the greatest amount of total VFA, significantly higher $(\mathrm{p}<0.01)$ than both control and nitrate treatments (Figure 2). Nitrate treatments caused an increase in the acetate:propionate (AP) ratio, the highest being free nitrate. The control and matrix did not differ statistically in their AP ratio. Production of VFAs did not differ among treatments up to $12 \mathrm{~h}$ sampling time, after which there was a noticeable change in pattern. Nitrate treatments, both encapsulated and free, suppressed production of n-butyrate, n-valerate, isovalerate, isobutyrate, acetate and propionate. The matrix produced the greatest molar amounts of these VFAs. However, there was no molar difference between the matrix and control as well as between the nitrate treatments

Table 1. Means of in vitro fermentation parameters over $48 \mathrm{~h}$

\begin{tabular}{|c|c|c|c|c|c|c|c|}
\hline \multirow{2}{*}{ Variable } & \multirow{2}{*}{ Control } & \multirow{2}{*}{ Nitrate } & \multirow{2}{*}{ Enc. Nit } & \multirow{2}{*}{ Matrix } & \multicolumn{3}{|c|}{ Significance } \\
\hline & & & & & Trt & Time & Trt $\times$ time \\
\hline$\overline{\mathrm{pH}}$ & $6.79^{\mathrm{ab} 1}$ & $6.80^{\mathrm{a}}$ & $6.78^{\mathrm{b}}$ & $6.75^{\mathrm{c}}$ & $* *$ & $* *$ & $* *$ \\
\hline Biogas (mL) & $54.27^{\mathrm{b}}$ & $43.73^{\mathrm{c}}$ & $44.93^{c}$ & $61.33^{\mathrm{a}}$ & $* *$ & $* *$ & $* *$ \\
\hline Ammonia-N (mg/100 mL) & $2.02^{\mathrm{d}}$ & $2.80^{\mathrm{b}}$ & $3.62^{\mathrm{a}}$ & $2.53^{\mathrm{c}}$ & $* *$ & $* *$ & $* *$ \\
\hline Methane (mL) & $3.73^{\mathrm{a}}$ & $0.89^{\mathrm{b}}$ & $0.91^{\mathrm{b}}$ & $4.02^{\mathrm{a}}$ & $* *$ & $* *$ & $* *$ \\
\hline Hydrogen (mL) & $0.08^{\mathrm{ab}}$ & $0.10^{\mathrm{a}}$ & $0.05^{\mathrm{b}}$ & $0.07^{\mathrm{b}}$ & $*$ & $* *$ & $* *$ \\
\hline Acetate $(\mathrm{mM})$ & $20.37^{\mathrm{b}}$ & $19.05^{\mathrm{d}}$ & $19.71^{\mathrm{c}}$ & $21.52^{\mathrm{a}}$ & $* *$ & $* *$ & $* *$ \\
\hline Propionate $(\mathrm{mM})$ & $6.90^{\mathrm{b}}$ & $6.00^{\mathrm{d}}$ & $6.34^{\mathrm{c}}$ & $7.33^{\mathrm{a}}$ & $* *$ & $* *$ & $* *$ \\
\hline n-Butyrate $(\mathrm{mM})$ & $2.78^{\mathrm{b}}$ & $1.54^{\mathrm{c}}$ & $1.55^{\mathrm{c}}$ & $2.95^{\mathrm{b}}$ & $* *$ & $* *$ & $* *$ \\
\hline n-Valerate (mM) & $0.48^{\mathrm{a}}$ & $0.35^{\mathrm{b}}$ & $0.35^{\mathrm{b}}$ & $0.48^{\mathrm{a}}$ & $* *$ & $* *$ & $* *$ \\
\hline Isobutyrate (mM) & $0.38^{\mathrm{a}}$ & $0.31^{\mathrm{b}}$ & $0.33^{\mathrm{b}}$ & $0.38^{\mathrm{a}}$ & $* *$ & $* *$ & $* *$ \\
\hline Isovalerate (mM) & $0.68^{\mathrm{a}}$ & $0.54^{\mathrm{b}}$ & $0.57^{\mathrm{b}}$ & $0.68^{\mathrm{a}}$ & $* *$ & $* *$ & $* *$ \\
\hline Total VFA (mM) & $31.60^{\mathrm{b}}$ & $27.79^{\mathrm{d}}$ & $28.84^{c}$ & $33.35^{\mathrm{a}}$ & $* *$ & $* *$ & $* *$ \\
\hline $\mathrm{A} / \mathrm{P}$ & $3.15^{\mathrm{c}}$ & $3.36^{\mathrm{a}}$ & $3.24^{\mathrm{b}}$ & $3.12^{\mathrm{c}}$ & $* *$ & $* *$ & $* *$ \\
\hline
\end{tabular}

Enc. Nit, encapsulated nitrate; Trt, Treatment; VFA, volatile fatty acid; A/P, acetate to propionate ratio. Means within a row not sharing the same letter ${ }^{(a, b, c)}$ differ significantly $(\mathrm{p}<0.05)$.

$* * \mathrm{p}<0.01 ; * \mathrm{p}<0.05$. 
A

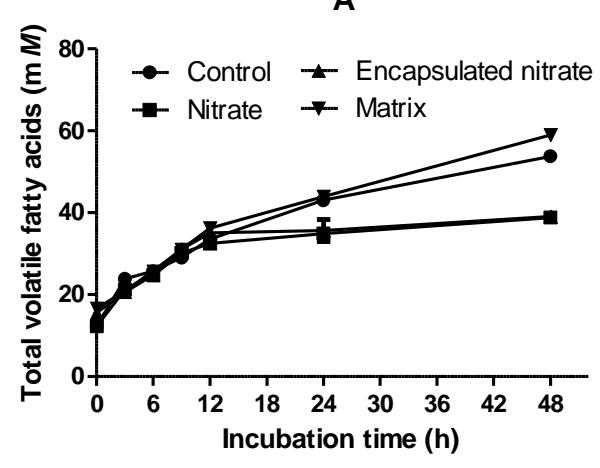

C

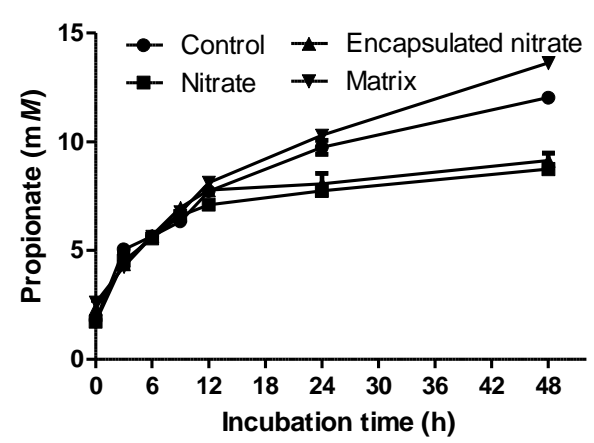

E

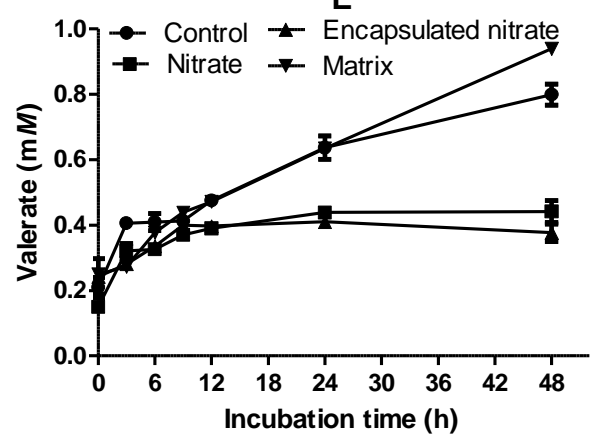

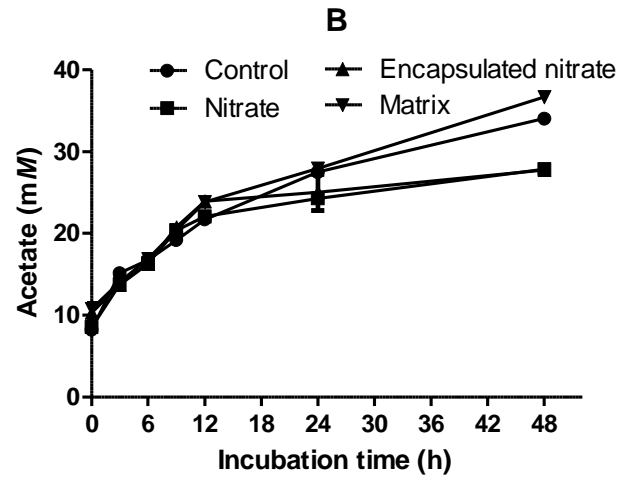

D

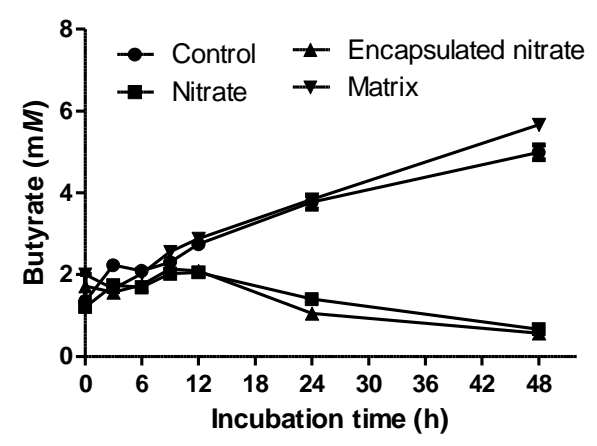

Figure 2. Graphs showing the production over time of total volatile fatty acids (A), acetate (B), propionate (C), butyrate (D), and valerate (E).

on n-butyrate, $\mathrm{n}$-valerate, isobutyrate, and isovalerate concentrations (Table 1).

Methane production was suppressed significantly $(\mathrm{p}<0.01)$ with the addition of nitrate, with both encapsulated and free form of nitrate producing a $76 \%$ decrease. There was a $7 \%$ increase with the matrix, although the production with the treatment was similar to the control (Figure 3A). There was no significant difference $(p>0.05)$ between the nitrate treatments throughout the study period, except at the $6 \mathrm{~h}$ sampling time (Figure 3B). Hydrogen production was significantly affected $(\mathrm{p}=0.014)$ by treatment. Significantly high $(p<0.05)$ hydrogen production was found in free nitrate treatment. The hydrogen in control and matrix treatment increased until $24 \mathrm{~h}$ incubation and thereafter decreased
(Figure 3C), whereas the hydrogen in free and encapsulated nitrate continuously increased (Figure 3D). Interestingly, the pattern of hydrogen production differed due to the presence of nitrate. There was more hydrogen production with free nitrate compared to the encapsulated form. However, there was no significant difference between the two treatments except at $24 \mathrm{~h}$.

\section{DISCUSSION}

Effect of encapsulating nitrate on ruminal $\mathrm{pH}$ and volatile fatty acids

There was no adverse effect on ruminal $\mathrm{pH}$ resulting from nitrate encapsulation as no significant difference was 
A

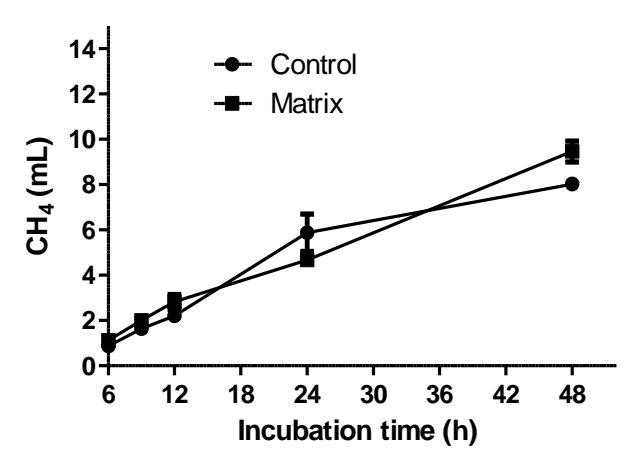

C

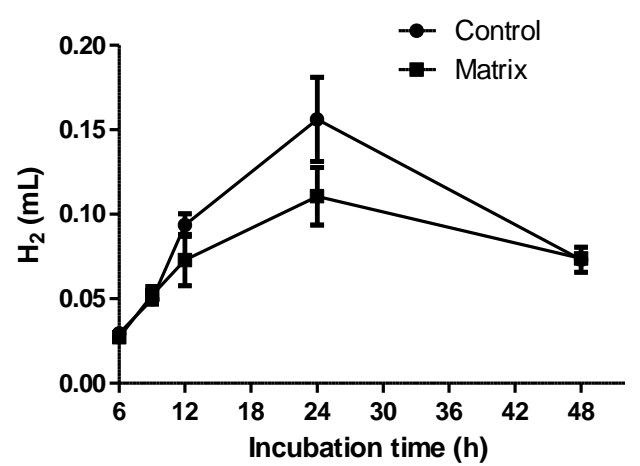

B

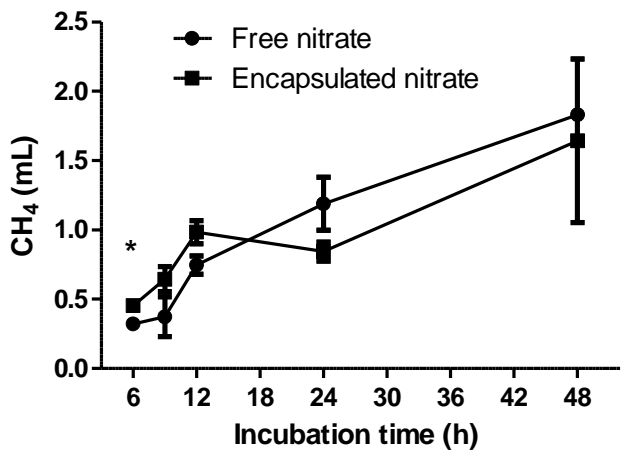

D

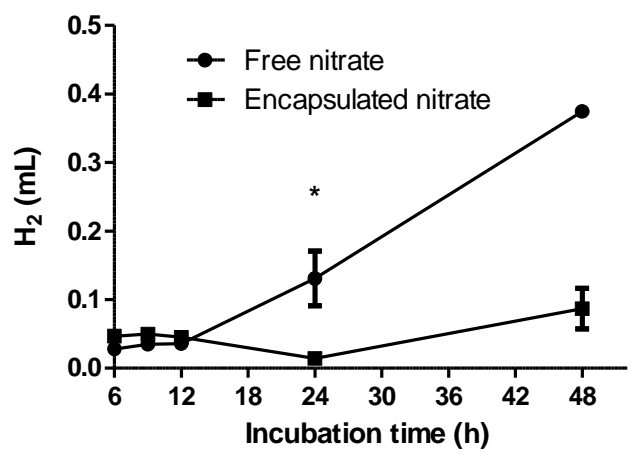

Figure 3. Gas composition of $\mathrm{CH}_{4}$ and $\mathrm{H}_{2}$ between control and matrix (A and C) and nitrate treatments (B and D). * Shows statistical difference $(\mathrm{p}<0.05)$.

observed between the control and encapsulated nitrate. Butyrate decreased to $0.57 \mathrm{mM}$ in the encapsulated treatment and $0.7 \mathrm{mM}$ with free nitrate (Figure 2D) as opposed to $5 \mathrm{mM}$ in control after $48 \mathrm{~h}$ of incubation. The decrease shows that nitrate was rapidly reduced, causing a diversion of electrons from butyrate formation to nitrate reduction ( $\mathrm{Li}$ et al., 2012). Methane and propionate production is suppressed in the presence of nitrate because of its higher affinity for $\mathrm{H}_{2}$ (Nolan et al., 2010). Nitrate reduction is thermodynamically favored over propiogenesis (Ungerfeld and Kohn, 2006), competing successfully for $\mathrm{H}_{2}$. This means that nitrate reduction diverts electrons from both methanogenesis and propiogenesis. In this study, acetate, valerate and propionate decreased significantly $(\mathrm{p}<0.01)$. Free nitrate resulted in less valerate, acetate and propionate concentrations than encapsulated nitrate. The decrease in total VFA concentrations upon nitrate addition has also been observed by other researchers (Sar et al., 2005; Van Zijderveld et al., 2010). Differences in sampling time after feeding can cause anomalies; Farra and Satter (1971) analyzed for VFAs after $1 \mathrm{~h}$ and found that acetate increased whilst propionate decreased.

\section{In vitro methane production}

Enteric methane production was reduced by $76 \%$, both with the encapsulated nitrate and the free form in comparison to control. Similar reduction in methane production, described as "one of the highest reduction rates" was reported in in vivo studies on sheep fed encapsulated fumarate (Wood et al., 2009). Nitrate has consistently been observed to lower enteric methane in several studies, from fermentative digestion in the rumen to secondary fermentation in systems such as anaerobic digesters to sediments (Leng and Preston, 2010). Methane production is significantly less when nitrate has been added, presumably due to successful competition for $\mathrm{H}_{2}$ by nitrateand nitrite-reducing microbes (Guo et al., 2009).

Due to slow release from the matrix, the reduction by encapsulation was slightly less than free nitrate by $3 \%$. Theoretically, it could be expected that the trend would follow this pattern throughout the study period, but for a longer time as nitrate will only be released in small doses. There was no significant difference between the two nitrate treatments throughout the study period, except at $6 \mathrm{~h}$. Thus, encapsulation did not have a negative effect on the fermentation profile in vitro.

Interestingly, with the matrix treatment $7 \%$ more methane was generated. Oilseed cakes and extractions contain the most important essential amino acids. Due to the screw-expeller method used in extracting sesame oil in this study, the protein obtained would be expected to not differ much from the meal or cake (Birthal and Rao, 2002). 
Sesame seed has high oil (42\% to $56 \%$ ) and protein (20\% to $25 \%$ ) contents (Deshpande et al., 1996; Kochhar, 2011). Oleic (36\% to $42 \%)$ and linoleic acids ( $42 \%$ to $50 \%)$ make up more than $80 \%$ of the total fatty acid composition (Hofer et al., 2009). Oleic, linoleic and linolenic oil addition to sheep diets have been shown to suppress methane production (Czerkawski et al., 1966; Johnson et al., 2002). In a recent study, sesame oil at a high dose was shown to be antimethanogenic (Santra et al., 2013). However, Johnson et al. (2002) in their study found that the oilseeds canola and cotton, which are abundant in C18 fatty acids, did not reduce methane production as would be expected. Shorter chain fatty acids have been found to be more effective at reducing enteric methane (Dong et al., 1997). Thus, the matrix in this study with SOC and gum (C18 fatty acids) did not reduce methane but rather increased it. The reason could be because the nutrient content of sesame coupled with the high fiber diet may have promoted growth of methanogenic bacteria. Further studies would need to be conducted to ascertain the microbial population dynamics on addition of this matrix.

\section{Ammonia nitrogen}

Significantly higher $(\mathrm{p}<0.01) \quad$ concentrations of ammonia were obtained in nitrate treatments than in the control and matrix. This would be expected as nitrate is reduced rapidly to nitrite and consecutively to ammonia. When high levels of nitrite accumulate, they are absorbed into the bloodstream where they change hemoglobin to methemoglobin, a condition known as methemoglobinemia. Methemoglobin cannot carry oxygen like hemoglobin (Patel et al., 2013), thus resulting in ill health or even death of the animal in severe cases. Encapsulated nitrate was released slowly, thus allowing for more rapid and complete reduction to ammonia when compared with free nitrate. This demonstrates the effectiveness of encapsulation, with the potential of reducing nitrite toxicity when used in animal feeds. Encapsulated nitrate produced double the amount of ammonia-N (44\%) in the matrix (20\%). Sesame oil and SOC is relatively high in protein, which could contribute to the ammonia-N in both treatments. This would suggest ammonia-N for encapsulated treatment was coming from both the degradation of the matrix and also from nitrate reduction. Therefore using sesame gum in encapsulation has the advantage of increasing protein bioavailability to ruminants.

\section{IMPLICATION}

Significant methane reduction obtained in in vitro fermentation with nitrate addition indicated the strong methane reduction potential of nitrate. Encapsulating nitrate in sesame gum does not affect its ability to reduce methane.
Nitrate reduction in the gum-encapsulated treatment yielded more ammonia, suggesting a slow release of nitrate, a property that can be harnessed for protection of animals against nitrite toxicity while achieving a rapid and complete reduction of nitrate to ammonia. Encapsulation of nitrate decreased acetate, propionate and butyrate. The result of this study suggests the potential for nitrate encapsulation in not only mitigating methane but also in reducing the risk of nitrate intoxication, protecting animal health and welfare.

\section{ACKNOWLEDGMENTS}

This study was supported by funds from IPET (Institute of Planning and Evaluation for Technology in Food, Agriculture, Forestry and Fisheries), and the work was also supported by Cooperation Research Project (PJ0100232014), Rural Development Administration, Republic of Korea.

\section{REFERENCES}

Aly, S. M. 1992. Degumming of soybean oil. Grasasy Aceites 43: 284-286.

Anal, A. K. and H. Singh. 2007. Recent advances in microencapsulation of probiotics for industrial applications and targeted delivery. Trends Food Sci. Technol. 18:240-251.

Birthal, P. S. and P. P. Rao. 2002. Technology options for sustainable livestock production in India. Proceedings of the Workshop on Documentation, Adoption, and Impact of Livestock Technologies in India. January 18-19, 2001; International Crops Research Institute for the Semi-Arid Tropics, Patancheru, India.

Brannon-Peppas, L. 1997. Polymers in controlled drug delivery. Biomaterials 11:1-14.

Chaney, A. L. and E. P. Marbach. 1962. Modified reagents for determination of urea and ammonia. Clin. Chem. 8:130-132.

Cooke, R. F., N. S. Del Río, D. Z. Caraviello, S. J. Bertics, M. H. Ramos, and R. R. Grummer. 2007. Supplemental choline for prevention and alleviation of fatty liver in dairy cattle. J. Dairy Sci. 90:2413-2418.

Cusack, P. M. V., N. P. McMeniman, and I. J. Lean. 2005. The physiological and production effects of increased dietary intake of vitamins $\mathrm{E}$ and $\mathrm{C}$ in feedlot cattle challenged with bovine herpesvirus 1. J. Anim. Sci. 83:2423-2433.

Czerkawski, J. W., K. L. Blaxter, and F. W. Wainman. 1966. The metabolism of oleic, linoleic and linolenic acids by sheep with reference to their effects on methane production. Br. J. Nutr. 20:349-362.

Deshpande, S., U. Deshpande, and D. Salunkhe. 1996. Sesame oil. Bailey's Industrial Oil and Fat Products 2:457-495.

Dong, Y., H. D. Bae, T. A. McAllister, G. W. Mathison, and K.-J. Cheng. 1997. Lipid-induced depression of methane production and digestibility in the artificial rumen system (RUSITEC). Can. J. Anim. Sci. 77:269-278.

Emanuele, S. M. 2006. Microencapsulation and its application in animal nutrition. In: Proceedings of the 4th Mid-Atlantic Nutrition Conference. Date; University of Maryland, College 
Park, MD, USA. pp 126-131.

Emanuele, S. M. and D. Putnam. 2006. Encapsulating nutrients to improve reproduction and nitrogen utilization in ruminants. In: Ruminant Nutrition Symposium. February 1-2, 2006; Best Western Gateway Grand, Gainesville FL, USA. pp. 1-2.

Erwin, E. S., G. J. Marco, and E. M. Emery. 1961. Volatile fatty acid analyses of blood and rumen fluid by gas chromatography. J. Dairy Sci. 44:1768-1771.

Farra, P. A. and L. D. Satter. 1971. Manipulation of the ruminal fermentation. III. Effect of nitrate on ruminal volatile fatty acid production and milk composition. J. Dairy Sci. 54:1018-1024.

Goel, G. and H. P. S. Makkar. 2012. Methane mitigation from ruminants using tannins and saponins. Trop. Anim. Health Prod. 44:729-739.

Guo, W. S., D. M. Schaefer, X. X. Guo, L. P. Ren, and Q. X. Meng. 2009. Use of nitrate-nitrogen as a sole dietary nitrogen source to inhibit ruminal methanogenesis and to improve microbial nitrogen synthesis in vitro. Asian Australas. J. Anim. Sci. 22:542-549.

Hofer, R., J. H. Clark, G. A. Kraus, P. Saling, P. Spicher, R. Schroder, M. Kaltschmitt, E. Dinjus, F. Seyfried, and K. Hill. 2009. Sustainable solutions for modern economies. Royal Society of Chemistry, Cambridge, UK. 203 p.

Johnson, K. A., R. L. Kincaid, H. H. Westberg, C. T. Gaskins, B. K. Lamb, and J. D. Cronrath. 2002. The effect of oilseeds in diets of lactating cows on milk production and methane emissions. J. Dairy Sci. 85:1509-1515.

Johnson, K. A. and D. E. Johnson. 1995. Methane emissions from cattle. J. Anim. Sci. 73:2483-2492.

Kochhar, S. P. 2011. Minor and speciality oils. In: Vegetable Oils in Food Technology: Composition, Properties and Uses 2nd Ed. (Ed. F. D. Gunstone). Wiley-Blackwell, Oxford, UK. 291 p.

Lee, J. H., J. C. Waller, S. L. Melton, A. M. Saxton, and L. O. Pordesimo. 2004. Feeding encapsulated ground full-fat soybeans to increase polyunsaturated fat concentrations and effects on flavor volatiles in fresh lamb. J. Anim. Sci. 82:27342741.

Leng, R. A. and T. R. Preston. 2010. Further considerations of the potential of nitrate as a high affinity electron acceptor to lower enteric methane production in ruminants. Livestock Res. Rural Dev. 22, Article \#221. http://www.lrrd.org/lrrd22/12/ leng22221.htm Accessed February 11, 2014

Li, L., J. Davis, J. Nolan, and R. Hegarty. 2012. An initial investigation on rumen fermentation pattern and methane emission of sheep offered diets containing urea or nitrate as the nitrogen source. Anim. Prod. Sci. 52:653-658.

Lopez, S., C. Valdes, C. J. Newbold, and R. J. Wallace. 1999. Influence of sodium fumarate addition on rumen fermentation in vitro. Br. J. Nutr. 81:59-64.

Macgregor, C. A., M. R. Knobbe, and A. J. Hugo. 2007. Method for manufacturing animal feed, method for increasing the rumen bypass capability of an animal feedstuff and animal feed. US 7297356 B2.
Martin, C., D. P. Morgavi, and M. Doreau. 2010. Methane mitigation in ruminants: from microbe to the farm scale. Animal 4:351-365.

McDougall, E. I. 1948. Studies on ruminant saliva. 1. The composition and output of sheep's saliva. Biochem. J. 43:99109.

Nazzaro, F., P. Orlando, F. Fratianni, and R. Coppola. 2012. Microencapsulation in food science and biotechnology. Curr. Opin. Biotechnol. 23:182-186.

Nolan, J. V., R. S. Hegarty, J. Hegarty, I. R. Godwin, and R. Woodgate. 2010. Effects of dietary nitrate on fermentation, methane production and digesta kinetics in sheep. Anim. Prod. Sci. 50:801-806.

Patel, P. A. S., S. C. Alagundagi, and S. R. Salakinkop. 2013. The anti-nutritional factors in forages-A review. Current Biotica 6: 516-526.

Ridwan, R., Y. Widyastuti, S. Budiarti, and A. Dinoto. 2010. Analysis of rumen microbial population of cattle given silage and probiotics using terminal restriction fragment length polymorphism. Microbiol. Indonesia 3:126-132.

Santra, A., A. Banerjee, and S. Das. 2013. Effect of vegetable oils on ciliate protozoa, methane yield, enzyme profile and rumen fermentation in vitro. Anim. Nutr. Feed Technol. 13:181-193.

Sar, C., B. Mwenya, B. Santoso, K. Takaura, R. Morikawa, N. Isogai, Y. Asakura, Y. Toride, and J. Takahashi. 2005. Effect of Escherichia coli wild type or its derivative with high nitrite reductase activity on in vitro ruminal methanogenesis and nitrate/nitrite reduction. J. Anim. Sci. 83:644-652.

Takahashi, J. 1989. Effect of nitrate content of forage on the production of volatile fatty acids by sheep rumen microbes in vitro. Jpn. J. Zootech. Sci. 60:476-483.

Ungerfeld, E. M. and R. A. Kohn. 2006. The role of thermodynamics in the control of ruminal fermentation. In: Ruminant Physiology: Digestion, Metabolism and Impact of Nutrition on Gene Expression, Immunology and Stress (Eds. K. Sejrsen, T. Hvelplund, and M. O. Nielsen). Wageningen Academic Publishers, Wageningen, The Netherlands, pp. 5585.

Van Zijderveld, S. M., W. J. J. Gerrits, J. A. Apajalahti, J. R. Newbold, J. Dijkstra, R. A. Leng, and H. B. Perdok. 2010. Nitrate and sulfate: Effective alternative hydrogen sinks for mitigation of ruminal methane production in sheep. J. Dairy Sci. 93:5856-5866.

Wood, T. A., R. J. Wallace, A. Rowe, J. Price, D. R. Yáñez-Ruiz, P. Murray, and C. J. Newbold. 2009. Encapsulated fumaric acid as a feed ingredient to decrease ruminal methane emissions. Anim. Feed Sci. Technol. 152:62-71.

Zhou, Z., Z. Yu, and Q. Meng. 2012. Effects of nitrate on methane production, fermentation, and microbial populations in in vitro ruminal cultures. Bioresour. Technol. 103:173-179. 